\title{
Activity of Guaiacol Peroxidase of Solanum Lycopersicum In presence of Detergents and Chaotropic Agents
}

\author{
Shahryar Saeidian \\ Assistant professor of Biochemistry, Department of Biology, payame noor university, Iran
}

\begin{abstract}
Browning of damaged tissues in fresh fruits and vegetables results mainly from the oxidation of phenolic compounds to quinones by peroxidase. The activation of Peroxidase by sodium dodesyl sulphat investigated, but reports on the effect of detergents and chaotropic agents on activity of Peroxidase are scarce. Here the effect of some detergents and chaotropic agent on activity of enzyme in soluble and in partial purified fraction was investigated. Sarkosyl inhibited activity of enzyme for oxidation of guaiacol and $\mathrm{H2O2}$, although has inhibitory effect in higher concentrations. Other ionic, Nonionic detergents and Chaotropic agents showed inhibitory effect on activity of Peroxidasein partial purified fraction. Inhibitory effect of Urea, GnHcl, NP-40, Triton $x-100$ and Sodium cholate in presence of these substrates investigated so GnHcl and NP40 showed that they are potent inhibitor of peroxidase and sodium cholate showed that it is a weak inhibitor of guaiacol peroxidase. Results identified and confirmed the differences in structure and conformation of enzyme in soluble and in partial purified fraction for oxidation of different substrates.
\end{abstract}

KEYWORD: Catechol, Pyrogallol, Purification, Sarkosyl

\section{INTRODUCTION}

Peroxidase (EC 1.11.1.7; donor:hydrogen-peroxide oxidoreductase, POD) is one of the key enzymes controlling plant growth, differentiation and development. The enzyme participates in construction, rigidification and eventual lignification of cell walls, biosynthesis of ethylene from 1-aminocyclopropane-1carboxylic acid and $\mathrm{H} 2 \mathrm{O} 2$, regulation of auxin level through auxin catabolism, protection of tissue from damage and infection by pathogenic microorganisms, the oxidation of indoleacetic acid [1,2]. In vitro, this enzyme is widely employed in microanalysis [3]. More than $80 \%$ of immunoenzymatic kits contain peroxidase as labeling enzyme. Recently, peroxidases have been used for biotransformation of organic molecules [4]. It has been well established that peroxidase as one of the most stable enzymes can contribute to deteriorative changes in quality of the processed products [5]. Enzymatic browning is one of the most important colour reactions that affect fruits and vegetables. It is catalyzed by polyphenoloxidases and peroxidases [6]. It was estimated that over 50 percent losses in fruits and vegetables occur as result of enzymatic browning [7]. Marshall et al. 2000 [8] reported that the rate of enzymatic browning in fruits and vegetables is governed by the active polyphenoloxidase and peroxidase content of the tissues, the phenolic content of the tissues, $\mathrm{pH}$, temperature and oxygen availability with the tissue. According to Khan and Robinson [9] the peroxidase is directly responsible for enzymatic browning in mangoes. The objective of this work was to study the effect of $\mathrm{pH}$ and heat on peroxidase activity and to extend the knowledge of vegetables peroxidase in particular.

\section{MATERIALS AND METHODS}

Chemicals: Thesmall cherry tomatoes used inthisstudy were obtainedfrom Kurdistan of Iranand frozenat$25^{\circ}$ Cuntil used. Guaiacol, polyvinylpyrolidone(PVPP), sodium cholate werepurchased from Merck(Darmstadt,Germany).Phenylmethylsulfonylfluoride (PMSF), nonaaethylene glycol octylphenol ether (Triton x-100), nonaethylene glycol octylphenyl ether (NP-40), urea and guanidine chloride (GnHcl)werepurchasedfromSigma-Aldrich(St. Louis, USA). Sarkosyl was purchased from Fluka;Allchemicalswere ofanalyticalgrade.

Enzyme Extraction: 250 grams of wild pears were homogenized in $200 \mathrm{~mL}$ of $0.1 \mathrm{M}$ phosphate buffer $(\mathrm{pH}$ 6.8) containing $10 \mathrm{mM}$ ascorbic acid and $0.5 \%$ polyvinylpyrrolidone with the aid of a magnetic stirrer for $1 \mathrm{~h}$. The crude extract samples were centrifuged at $30000 \mathrm{~g}$ for $20 \mathrm{~min}$ at $4^{\circ} \mathrm{C}$. Solid ammonium sulphate (NH4)2SO4 was added to the supernatant to obtain30 and $80 \%$ (NH4)2SO4 saturation, respectively. After $1 \mathrm{~h}$, the precipitated proteins for each stage were separated by centrifugation at $30000 \mathrm{~g}$ for $30 \mathrm{~min}$. The precipitate was redissolved in a small volume of distilled water and dialyzed at $4^{\circ} \mathrm{C}$ against distilled water for $24 \mathrm{~h}$ with 4 changes of the water during dialysis. 
Protein Determination: Protein contents oftheenzyme extracts were determined according tolowry method using bovine serumalbuminasastandard [10].

Enzymatic activity assays: Partial purified Peroxidase activity was determined spectrophotometrically by following, at a specific wavelength, the increase in absorbance due to the oxidation of a selected substrate to its corresponding o-quinone. Namely, the increase in absorbance was followed at $420 \mathrm{~nm}$ in order to monitor the oxidation of, guaiacole. Assays were conducted at room temperature $\left(\sim 22-25^{\circ} \mathrm{C}\right)$, in a 3-ml reaction mixture prepared as follows: to $2.9-2.97 \mathrm{ml}$ of $0.1 \mathrm{M}$ phosphate buffer, $\mathrm{pH} 6.5$, containing the appropriate amount of substrate prepared in the same buffer, an aliquot $(75 \mu 1)$ of Small cherry tomato extract was added. Enzymatic activity was determined by measuring the increase in absorbance at $420 \mathrm{~nm}$ for guaiacol with a spectrophotometer (6305 JENWAY). In order to correct for substrate autoxidation, the reaction mixture, was placed in the sample cuvette while the reference cuvette contained buffer and the substrate. Enzyme activity was calculated from the linear portion of the curve. Appropriate aliquots of $5 \mathrm{mM}$ detergents and agents prepared in $0.1 \mathrm{M}$ phosphate buffer, $\mathrm{pH} 6.8$, were added to the reaction mixture just before addition of the small cherry tomato extract. The final volume of the reaction mixture was always $3 \mathrm{ml}$.

Effect of Detergents and Chaotropic Agents:The enzymatic activity were also measured in the presence of increasing concentrations of ionic detergents( Sodium cholate and sarkosyl), Nonionic detergents(Triton x-100 and NP-40) and Chaotropic agents (Urea and $\mathrm{GnHcl}$ ). The concentrations used in each case were kept within the range where no aggregation was observed and were determined as a function of the sensitivity of the enzymatic activity. Enzymatic activity of Peroxidase assayed in extract and in partially purified Peroxidase separately.

Activity Assayes in the presence of Ionic Detergents: The Peroxidase activity was assayed in $0.1 \mathrm{M}$ phosphate buffer at $\mathrm{pH} 6.5$ with $200 \mathrm{mM}$ guaiacoland $10 \mathrm{mM}$ of $\mathrm{H} 2 \mathrm{O} 2 \mathrm{as}$ the substrates, respectively, in the presence of different concentrations ofsarkosyl and sodium cholate. The concentration ranges remained below the critical micelle concentration(CMC) for each detergents.

Activity Assays in the presence of Non Ionic Detergents: The Peroxidase activity was assayed in $0.1 \mathrm{M}$ phosphate buffer at pH 6.5 with $200 \mathrm{mM}$ guaiacol and $10 \mathrm{mM}$ of $\mathrm{H} 2 \mathrm{O} 2$, respectively, as the substrates, in the presence of different concentrations of Triton $\mathrm{x}-100$ and $\mathrm{Np}-40$. The concentration ranges remained below the critical micelle concentration $(\mathrm{CMC})$ for each detergents.

Activity Assayes in the presence of chaotropic Agents: The Peroxidase activity was assayed in $0.01 \mathrm{M}$ phosphate buffer at $\mathrm{pH} 6.5$ with $200 \mathrm{mM}$ guaiacol and $10 \mathrm{mM}$ of $\mathrm{H} 2 \mathrm{O} 2$ as the substrates in the presence of different concentrations of urea or GnHcl. PEROXIDASE activity assayed at extract and partially purified Peroxidase, separately.

\section{RESULTS}

Assays conduct with small cherry tomatoes crude extract at pH 6.5: Peroxidase activity in presence of guaiacol and $\mathrm{H} 2 \mathrm{O} 2$ assayed as described in materials and methods, were detectable in tomatoes extract. Under our experimental conditions, no lag period was observed in the expression of either activity.

Effect ofIonic detergents. Effect of sarcosyl : The addition up to $0.3 \mathrm{mM}$ sarkosyl to the reaction mixture resulted up to a $25 \%$ decrease in the activity when guaiacol and $\mathrm{H} 2 \mathrm{O} 2$ were used as the substrate at $\mathrm{pH} 6.5$ (Figure 1). Higher detergent concentration up to $1 \mathrm{mM}$ caused a $45 \%$ decrease in Peroxidase activity with guaiacol and $\mathrm{H} 2 \mathrm{O} 2$ as the substrates. Over the concentration range $(0-1 \mathrm{mM})$, sarkosyl had inhibitory effect on Peroxidase activity in presence of guaiacol and $\mathrm{H} 2 \mathrm{O} 2$, although higher concentrations of sarkosyl, cloudiness prevented further investigations with these substrate( table 1).

Effect of sodium cholate: In the presence of sodium cholate at $\mathrm{pH}$ 6.5, a decrease in Peroxidase activity was observed when guaiacol and $\mathrm{H} 2 \mathrm{O} 2$ were used as the substrate. The inhibition increased with increasing detergent concentration, until a plateau was reached. In the presence of sodium cholate $(1 \mathrm{mM})$, the Peroxidase activity decreased progressively to $80 \%$ of the control.The detergent concentration increased progressively to $1 \mathrm{mM}$ in presence of guaiacol and $\mathrm{H} 2 \mathrm{O} 2$.Peroxidase activity reached to $65 \%$, so, showed $20 \%$ Inhibition of Peroxidase. In the presence of higher sodium cholate concentrations $(3 \mathrm{mM})$, the Peroxidase activity was reduced to $65 \%$ of the control(Figure 2). 
Effect of Nonionic detergents at pH 6.5: The addition of Triton $\mathrm{x}-100$ or NP-40 to the reaction mixture at $\mathrm{pH}$ 6.5 led to a decrease in the Peroxidase activity, whether guaiacol and $\mathrm{H} 2 \mathrm{O} 2$ were used as the substrates. The extent of inhibition, however varied with the detergent used. With guaiacol and $\mathrm{H} 2 \mathrm{O} 2$, up to $75 \%$ inhibition was observed in the presence of $2 \mu \mathrm{M}$ of triton $\mathrm{x}-100.70 \%$ inhibition was observed in the presence of $2 \mu \mathrm{M}$ NP-40 (Figure 3).Over the same ranges of concentrations(4 $\mu \mathrm{M}$ for tritonx-100 and NP-40), no effect was observed on Peroxidase activity when guaiacol and $\mathrm{H} 2 \mathrm{O} 2$ were used as the substrate. Activity of Peroxidase decreased in presence of triton-100 and NP-40 as detergents.

Effect of Chaotropic Agents: The addition of increasing of urea to the assay mixture at $\mathrm{pH} 6.5$ resulted in increasing inhibition of the Peroxidase activity, so that 50\% inhibition was reached with $100 \mathrm{mM}$ urea and increasing of ureaconcentration up to $300 \mathrm{mM}$ caused only $70 \%$ inhibition in Peroxidase activity inpresence of guaiacol and $\mathrm{H} 2 \mathrm{O} 2$; no further inhibition was observed for up to $350 \mathrm{mM}$ urea (Figure 4).

Effect of GnHcl: Up to $45 \%$ and $70 \%$ inhibition of Peroxidase activity was observed for catechol oxidation in presence of 100 and $300 \mathrm{mM} \mathrm{GnHcl,} \mathrm{respectively.No} \mathrm{further} \mathrm{inhibition} \mathrm{was} \mathrm{observed} \mathrm{for} \mathrm{up} \mathrm{to} 350 \mathrm{mM}$ urea (Figure 4).

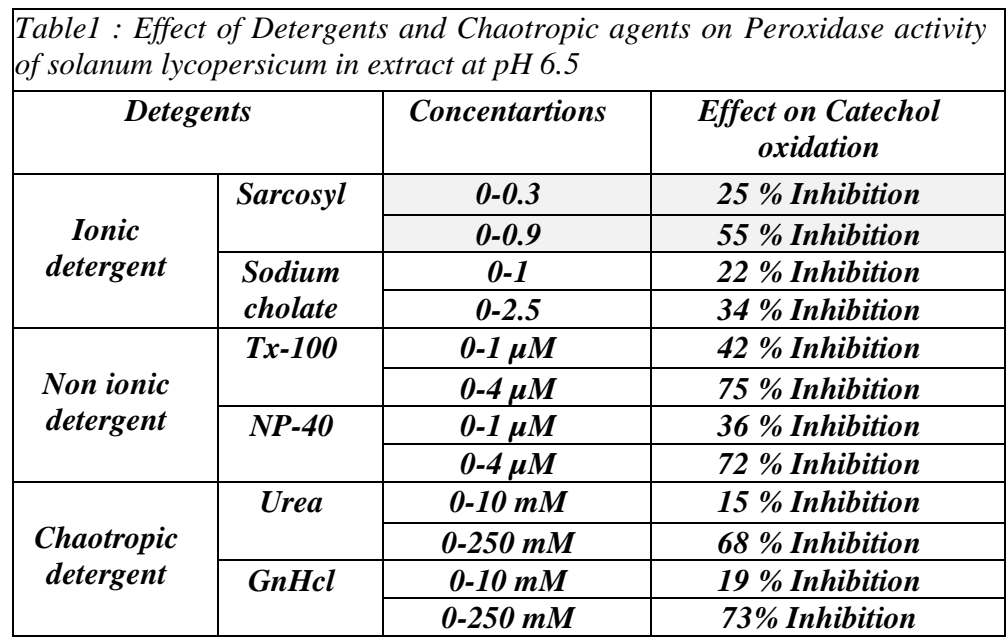

\section{DISCUSSION}

The present investigation was conducted on extracts obtained from small cherry tomato. The extract prepared as described in the Materials and Methods consisted of the soluble fraction of the fruit homogenate and the Peroxidase activity reported here refer to the soluble enzyme. Each assay was performed at least in triplicate and each experiment was repeated three times. The results were expressed as means of the values obtained and the standard deviations of the means were calculated and shown on the figures. Peroxidase retains its intriguing property of being able to exist in a latent form which it can be released by a variety of treatments, such as exposure to activators that are reputed to inactive enzymes [11]. Sarkosyl would inhibit small cherry tomato Peroxidase activity for oxidation guaiacol and $\mathrm{H} 2 \mathrm{O} 2$ exhibited different sensitivities toward the various detergents and agents used. Peroxidase activity for oxidation of guaiacol and $\mathrm{H} 2 \mathrm{O} 2$ was sensitive to detergent/agent concentrations the same as activity of Peroxidase for pyrogallol and catechol oxidation[12]. Our results showed that among the detergents/agents tested in this study sarkosyl would inhibitPeroxidasethe same as other detergents that inhibited the enzyme activity. The inhibition observed with sodium cholate may be due to steric hindrance upon binding of this bulkier detergent to the enzyme. Nonionic detergents were larger than sodium cholate and may cause inhibition upon binding to the enzyme by preventing acces of the substrate to the active site because of steric hindrance [19]. The present study shows that Peroxidase in solanum lycopersicum are inhibited by sarkosyl and by urea and other detergents. Interestingly, while no more than $70 \%$ inhibition was observed in the presence of up to $300 \mathrm{mM}$ urea for oxidation of guaiacol and $\mathrm{H} 2 \mathrm{O} 2$. Similarly, GnHcl caused no more than $75 \%$ inhibition of Peroxidase for oxidation of guaiacol and $\mathrm{H} 2 \mathrm{O} 2$. Thus activity of soluble Peroxidase of solanum lycopersicum was sensitive to chaotropic agents and nonionic detergents for oxidation of these substrates. These finding indicated probably a difference in the conformational and in the microenvironment of the respective active site in the enzyme. 


\section{ACKNOWLEDGMENT}

This work was superoxidaserted in part by the University of Payame Noor, and was done in exploratory laboratory of biochemistry in payame noor of saghez (Kurdistan).

\section{REFFERENCES}

[1.] H.B. Dunford (1991). Horseradish peroxidase: structure and kinetic properties. In: Everse J, Everse KE, Grisham MB (eds.) Per $\neg$ oxidase in Chemistry and Biology (pp. 1-24) CRC Press, Boca Raton, FL.

[2.] K. Wakamatsu and U. Takahama (1993). Changes in peroxidase activ 7 ity and peroxidase isoenzymes in carrot callus. Physiology of Plants 88: 167-171

[3.] H.W. Krell (1991). Peroxidase. An important enzyme for diagnostic test kits. In: Lobarsewski J, Greppin H, Penel C and Gaspar Th (eds.) Biochemical, Molecular and Physiological Aspects of Plant Peroxidases (pp. 469-478) Univ. M. Curie-Sklodowska and Univ. Geneva, Lublin and Geneva.

[4.] W. Adam. M. Lazarus, C.R. Saha-Moller, O. Weichold, U. Hoch and P. Schreier, (1999), Biotransformations with peroxidases. Advance Biochemical Engineering 63: 74-108.

[5.] D.W. Stanley, M.C. Bourne, A.P. Stone and W.V. Wismer. (1995). Low temperature blanching effects on chemistry, firmness and structure of canned green beans and carrots. Journal of Food Science 60: 327-333.

[6.] Y. Jiang, X. Duan . D. Joyce, Z.Li.J Zhang (2004). Advances in understanding of enzymatic browning in harvested litchi fruit. Food Chemistry 88: 443-446.

[7.] J.R. Whitaker and C.Y. Lee. (1995). Recent advances in chemistry of enzymatic browning. In Lee, C. Y. and Whitaker, J. R. eds. Enzymatics Browning and it's prevention, p. 2-7. ACS symposium series 600, Washington, DC, America Chemical Society.

[8.] Marshall, M.R., Kim, J., and Wei, C.I., 2000. Enzymatic browning in fruits, vegetable and seafoods. Journal of Food and Agriculture Organization, 41, 259-312.

[9.] A.A. Khan and D.S. Robinson. (1993). Purification of anionic peroxidase isoenzyme for mango (Mangifera indica L. var. chaunsa). Food Chemistry 46: 61-64.

[10.] O.H. Lowry, N.J. Rosebrough, A.L. Farr and R.J. Randall. (1951). Protein measurement with the Folin-Phenol reagents. J. Biol. Chem. 193: 265-27.

[11.] Gandia-Herrero F, Jimenez-Atienzar M, Cabanes J, Garcia-carmona F, Escribano J. Differential activation of a latent Peroxidase mediated by sodium dodesyl sulphate. J. Agric. Food Chem. 2005, 53, 6825-6830.

[12.] Saeidian S, Keyhanie E and Keyhanie J. Effect of ionic detergents, Nonionic detergents, and Chaotropic agents on peroxidase activity from dormant saffron(Crocus sativus L.) corms. J. Agric. Food Chem. 2007, 55, 3713-3719.

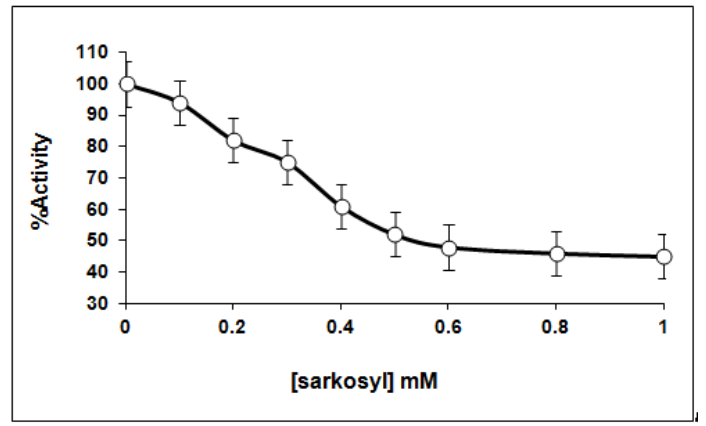

Figure 1. Effect of sarkosyl concentrations on small cherry tomato peroxidase activity in presence of guaiacol $200 \mathrm{mM}$ and $\mathrm{H} 2 \mathrm{O} 210 \mathrm{mM}$. The reaction medium at $25^{\circ} \mathrm{C}$ contained $0.1 M$ sodium phosphate buffer, $\mathrm{pH} 6.5$ and increasing concentrations of sarkosyl( 0 to $1 \mathrm{~m} M)$.

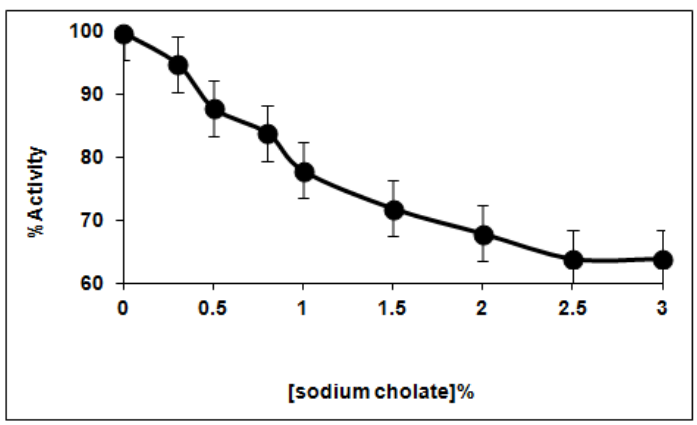

Figure 2. Effect of sodium cholate concentrations on small cherry tomato peroxidase activity in presence of guaiacol $200 \mathrm{mM}$ and $\mathrm{H} 2 \mathrm{O} 210 \mathrm{mM}$. The reaction medium at $25^{\circ} \mathrm{C}$ contained $0.1 \mathrm{M}$ sodium phosphate buffer, $\mathrm{pH} 6.5$ and increasing concentrations of sodium cholate $(0$ to $3 \mathrm{mM})$. 

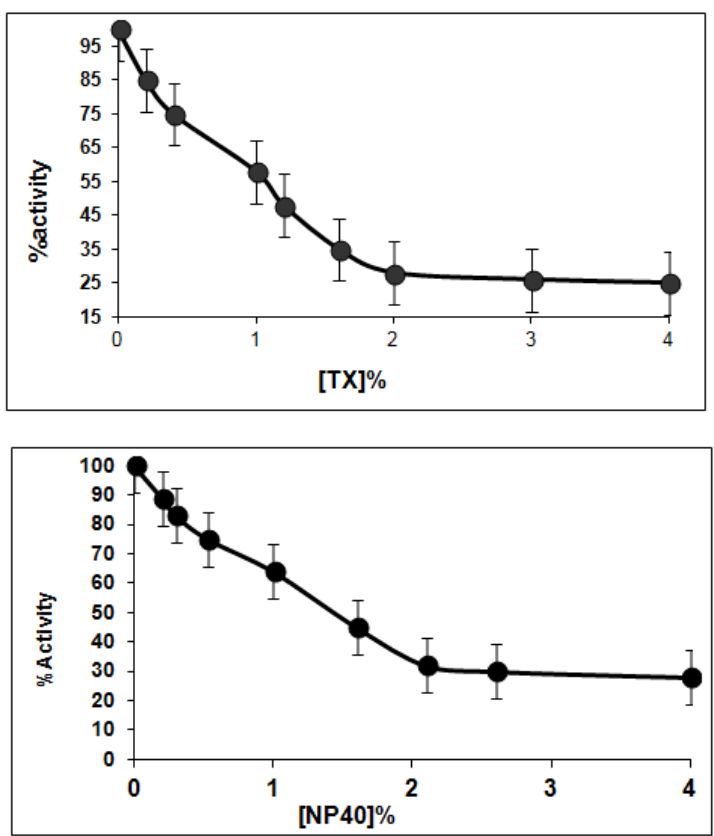

Figure 6. Effect of NP-40 and Triton $\mathrm{x}-100$ concentrations on partial purified peroxidase activity of small cherry tomato in presence of pyrogallol $15 \mathrm{mM}$. The reaction medium at $25{ }^{\circ} \mathrm{C}$ contained $0.1 \mathrm{M}$ sodium phosphate buffer, pH 6.8 and increasing concentrations of Triton $\mathrm{x}-100$ and NP-40(0 to $5 \mu M)$.
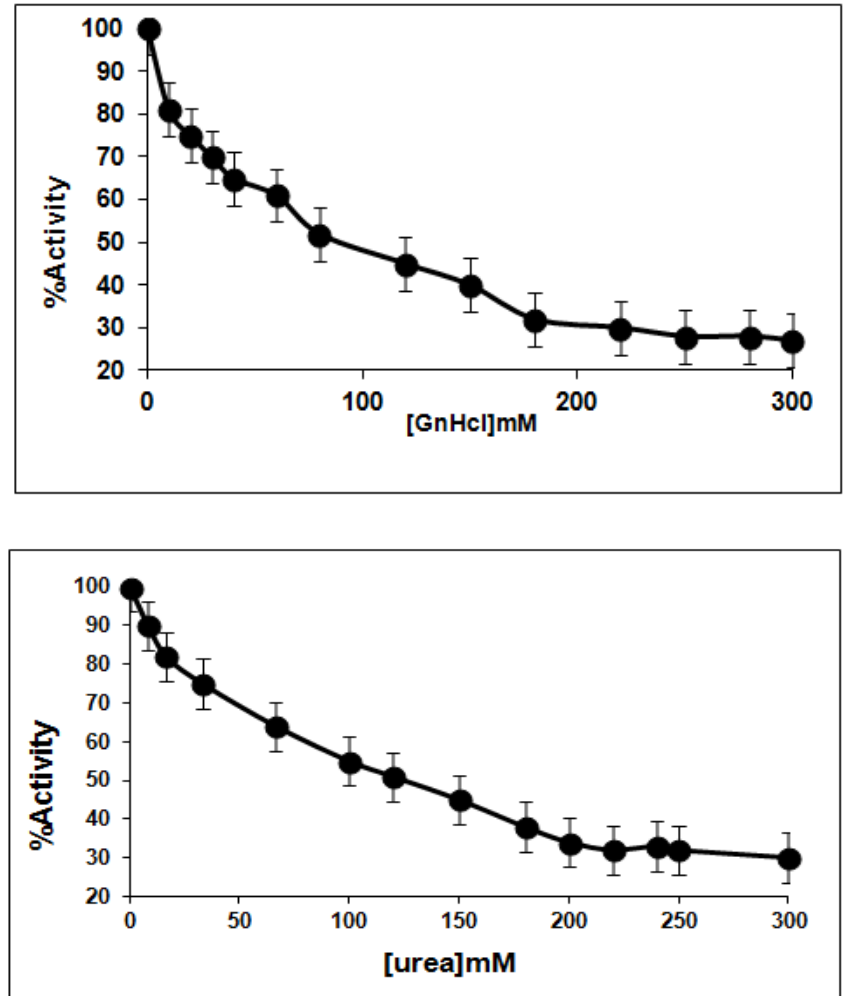

Figure 4. Effect of guanidine hydro chloride $(\mathrm{Gn} . \mathrm{Hcl})$ and Urea concentrations on small cherry tomato peroxidase activity in presence of pyrogallol $15 \mathrm{mM}$. The reaction medium at $25{ }^{\circ} \mathrm{C}$ contained $0.1 \mathrm{M}$ sodium phosphate buffer, $\mathrm{pH} 6.8$ and increasing concentrations of $\mathrm{Gn} . \mathrm{Hcl}$ and urea(0 to $350 \mathrm{mM})$. 